\title{
AN EMPIRICAL EXAMINATION OF THE RELATIONSHIPS AMONG CREATIVITY, THE EVALUATION OF CREATIVE PRODUCTS, AND COGNITIVE STYLE AMONG CHINESE UNDERGRADUATES
}

Dr. Kuan-Chen Tsai, Department of Fashion Design, Asia University, Taiwan E-mail: tsaikuanchen@gmail.com

A R T I C L E I N F O

Original Research

Received: December, 15.2017.

Revised: March, 03.2018.

Accepted: March, 29.2018.

doi:10.5937/ijcrsee1801053T

UDK

159.922.072

\section{Keywords:}

creativity,

creative products,

cognitive style,

SEM.

\begin{abstract}
A B S T R A C T
The current study investigates creativity from a creative product perspective. More specifically, we want to know if a connection exists between an individual's creativity and his or her evaluation of creative products. We also want to know what role cognitive style plays in this relationship. The sample (139 second-year undergraduates) was collected from an art and design program of an institution in Macau. Convenience sampling was used for the current study. The present study found partial support for the associations between cognitive style, creativity, and evaluations of creative products. Based on zero-order correlations, visual and verbal cognitive styles were moderately and positively correlated to three components of CPSS (novelty, resolution, and elaboration and synthesis). The results of the SEM further confirm this relationship between cognitive style and CPSS $(r=.69, p<.05)$.
\end{abstract}

(C) 2018 IJCRSEE. All rights reserved.

\section{INTRODUCTION}

A significant number of studies from different fields, including cognitive and developmental psychology, neuroscience, education, business management, and arts, have contributed to advancing our understanding of creativity in people (Hadani and Jaeger, 2015). With regard to assessing creativity, asking respondents to produce creative products is considered one of the more valid methods (Kaufman, Bear, and Cole, 2009; Tsai, 2016a). As Kaufman and Baer (2012) state, "when it comes to judging real-world creative products ... they ask experts. Not everyone will agree with every expert opinion. Yet there is no higher court of appeal" (pp. 83-84).

Corresponding Author

Dr. Kuan-Chen Tsai, Department of Fashion Design,

Asia University, Taiwan

E-mail: tsaikuanchen@gmail.com

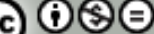

BY NO ND

This work is licensed under a Creative Commons Attribution - NonCommercial - NoDerivs 4.0. The article is published with Open Access at www.ijcrsee.com
Runco, Paek, and Jaeger (2015) examined funded papers published by three major journals related to creativity: Creativity Research Journal; Psychology of Art, Creativity, and Aesthetics; and Journal of Creative Behavior. Among them, the topic of creativity accounted for $22.5 \%$ of a total of 707 papers. They also found that three major funding sources supporting research on creativity and giving out the largest number of awards were in Asia: the National Science Foundation, Ministry of Education of China, and Social Sciences and humanities Research Council of Canada. Although these numbers reported in their paper were remarkable, the authors concluded that creativity research is still not supported in the global market.

Although creativity is regarded as an important topic in society as a whole, it seems that the market for creativity is nowhere near its full possible momentum. Therefore, the current study investigates creativity from a creative product perspective. More specifically, we want to know if a connection exists between an individual's creativity and his or her evaluation of creative products. We also want to know what role cognitive style plays 
in this relationship. To our knowledge, the empirical studies examining these three variables are limited; more research is needed to explore this line of thought.

Creativity and imagination are used interchangeably. Creativity is treated as complex and multifaceted in nature; there is no universally accepted definition of creativity in the literature. With regard to the characteristics of creativity characteristics, Treffinger, Young, Selby, and Shepardson (2002) clustered four categories: generating ideas, digging deeper into ideas, openness and courage to explore ideas, and listening to one's inner voices. Generating ideas concerns cognitive abilities such as divergent thinking, creative thinking, or metaphorical thinking. Digging deeper into ideas is related to cognitive characteristics such as convergent thinking or critical thinking. The openness and courage to explore ideas category involves addressing some personality traits. Finally, listening to one's inner voice concerns a level of personal understanding, vision, and commitment (viii).

In their white paper on promoting creativity in children, Hadani and Jaeger (2015) argue that seven critical components that should be addressed for successfully facilitating creativity in the classroom: (a) imagination and originality: pretend play is an effective tool for children to exercise their imagination and express original ideas; (b) flexibility: exposing children to diverse experiences and encouraging them to be open minded will enhance flexible thinking, which is an important element in the creative process; (c) decision-making: creative ideas stem from three stages-problem identification, divergent thinking, and evaluation-and it is a cyclical process - namely, developing accurate evaluations about what is best and creative idea is an important skill to learn; (d) communication and self-expression: effective communication is an important tool for not only expressing an individual's unique ideas but also making audiences understand them-metaphor and humor are two vital devices to express thoughts; (e) motivation: when children are intrinsically motivated without the promise of a reward, they are more likely to be creative; (f) collaboration: successful peer collaboration can lead to important contributions to group creativity; and finally, (g) action and movement: regular exercise and physical motion can boost children's creative potential. Overall, Hadani and Jaeger delineated their arguments supported by empirical studies and most importantly, they also provided useful tips and activities to enhance children's creativity in their appendix.

With regard to creativity assessment, Treffinger, Young, Selby, and Shepardson (2002) pointed out four different approaches to gather data about individuals' creative potential: (a) behavior or performance data (actual creative products and performances); (b) self-report data (e.g., attitude inventories, personal checklists, or biographical inventories); (c) rating scales (e.g., using ratings by teachers, parents, or peers); and (d) tests administrated under standardized conditions. Treffinger, Young, Selby, and Shepardson (2002) further suggested that it is unwise to count on a single instrument to capture individuals' creative strengths (xii-xiii).

According to the monograph of Treffinger, Young, Selby, and Shepardson (2002), creativity can be measured and, most importantly, creativity can be assessed in a systematic manner. A number of scholars have proposed different definitions of creativity that place different emphasis on creativity. Among them, creative products and outcomes are one of the approaches for assessment (Tsai, 2016b).

Several students of creativity believe that evaluating creative products or performance via experts in that domain is superior to other methods because this seems to better reflect individual real-life creativity (Baer and McKool, 2009; Carson, Peterson, and Higgins, 2005). Among them, Amabile (1982) proposed a consensual definition of creativity: "a product or response is creative to the extent that appropriate observers independently agree it is creative. Appropriate observers are those familiar with the domain in which the product was created or the response articulated" (p. 1001). Based on Amabile's consensual assessment technique (CAT), a number of requirements and procedures are needed for properly assessing creative products: first, expert judges who are familiar with the domain need to be recruited; second, the judges must make their assessments independently; third, these judges should not be given specific criteria for judging creativity; and fourth, judges should be instructed to rate the products relative to one another on the dimensions in question (p. 1002).

The main reason for supporting this method is grounded in the notion that "Nobel prize committees do not apply rubrics, complete checklists, or score tests. What do they do? They ask experts. The most valid assessment of the creativity of an idea or creation in any field is the collective judgment of [the] recognized experts in that field" (Baer and 
McKool, 2009, p. 2). One of the merits of the CAT is the ability to measure gardenvariety creative products. More specifically, as Kaufman, Lee, Baer, and Lee (2007) pointed out, "there is no more objective or valid measure of the creativity of a work of art than the collective judgments of artists and art critics" (p. 98). As a result, many creativity scholars highly support the use of CAT, in the assessment of individuals' creativity (Kaufman, Baer, Cole, and Sexton, 2009).

Cognitive style refers to how people process and represent information (Mayer and Massa, 2003). From this perspective, individuals can be differentiated from visualizers and verbalizers, where the former prefer using images to process and present information, and the latter prefer using words. Mayer and Massa (2003) examined 14 measures by using exploratory factor analysis with varimax rotation and the results suggested that the visualizer-verbalizer dimension is multifaceted, including individual differences in ability, style, and preference. More specifically, for cognitive ability, people with high spatial ability have a tendency of high proficiency in creating and manipulating spatial representations. As far as cognitive style is concerned, visualizers usually prefer visual modes of thinking. Finally, regarding learning preference, visual learners prefer instructions involving pictures.

Cognitive style has been extensively researched in the education literature. For example, there are studies on learning systems (Lo, Chan, and Yeh, 2012), academic performance (Al Salameh, 2011), spatial experiences (Erkan Yazici, 2013), self-efficacy (Harder, Czyzewski, and Sherwood, 2015), and learning strategies (Shi, 2011). A number of studies have focused on the relationships between cognitive styles and creativity (e.g., Dew, 2009; Kozhevnikov, Kozhevnikov, Yu, and Blazhenkova, 2013; Noppe, 1985; Pektas, 2010). These studies suggest that different cognitive styles have effects on real-life creative behavior. For instance, after conducting a battery of cognitive tests on Canadian college students, Choi and Sardar (2011) used a stepwise regression analysis to find that spatial abilities predicted visual cognitive style and in turn predicted visual learning preferences. Vocabulary knowledge predicted verbal cognitive style, but not verbal learning preferences. Based on the object of the study, our sample was art and design undergraduates; therefore, the current study especially employed visualverbal preferences as their cognitive style, which might reflect the specific nature of our subjects

The main purpose of the current study was to explore the interrelationships among individuals' creativity, their ability to assess creative products, and their cognitive styles. The unique contribution of the present study lies in the composition of the sample. The current study recruited art and design students to provide more information for art and design educators to facilitate creativity in their classrooms. Another important contribution is to that the scarce research concerning the three target variables (individuals' creativity, their ability to assess creative products, and their cognitive styles). Thus, following this line of thoughts, we asked two questions: (a) Is there a relationship among creativity, evaluating creative products, and cognitive style? And (b) if so, what is the interaction among these relationships?

\section{MATERIALS AND METHODS}

The sample was collected from an art and design program of an institution in Macau. Convenience sampling was used for the current study. Participants were 139 secondyear Chinese undergraduates recruited from five classes; among them 81 were women, and 58 were men. The average age of the students was 21.11 years $(\mathrm{SD}=3.35$ years). These recruited students received 40 MOP (about 5 USD) as their incentive for participating in the study. All participants signed consent forms and were assured of confidentiality and anonymity.

The Creative Product Semantic Scale (CPSS; Besemer and O’Quin, 1986) was used as a measurement to evaluate creative products. The development of the CPSS was based on the Creative Product Analysis Matrix (CPAM; Besemer and Treffinger, 1981), which is intended to help nonpractitioners evaluate creative products in a systematic manner. The CPSS involves three dimensions-novelty, resolution, and elaboration and synthesisand is scored on a 7-point Likert-type scale with 55 item pairs. Each of the nine subscales is created using four or five items of pairs of adjectives (Besemer, 1998).

For our study, we used a 15-item CPSS (White, Shen, and Smith, 2002), which was translated from English to Chinese by the researcher, collected from the original 55-item CPSS, with three of the eleven original subscales being used - originality, logic, and well craftedness. Each of the three subscales had 
five items, which consisted of three dimensions: novelty, resolution, and elaboration and synthesis. The main reason for using this abridged version of the CPSS was that Karen O'Quin, one of the scale's original developers, recommended that the 15-item CPSS can avoid the fatigue created among evaluators by using the longer instrument (White et al., 2002). The scoring of the CPSS is constructed by taking the mean of the items that make up the sub-scale. For example, the subscale original has five items (pairs of adjectives): overused-fresh, predictable-novel, usual-unusual, unique-ordinary, and original-conventional. A participant's score for original is computed by taking the mean of the scores of these items. Finally, the scoring of the CPSS of the three dimensions was done by using the average scores of three chair works for evaluation. Regarding reliability analyses for the CPSS, Besemer, 1998 reported a coefficient alpha for the novelty dimension from .84 to .86 , for resolution from .79 to .85 , and for elaboration and synthesis from .84 to .87 . Additionally, through the use of confirmatory factor analysis, a three-factor model was also confirmed and validated.

Abbreviated Torrance Test for Adults (ATTA; Goff and Torrance, 2002), a shortened version of the Torrance Test of Creative Thinking (TTCT; Torrance, 1966), was used to measure creative thinking ability. The ATTA uses three tasks (one verbal task and two figural tasks) to measure the creativity of adults by quantifying figural and verbal creative potentials, which consist of four abilities: fluency (quantities of produced ideas), originality (uncommon or unique ideas), elaboration (embellishing ideas with details), and flexibility (processing information in different ways). In our study, fluency, originality, elaboration, and flexibility were calculated, guided by the ATTA manual.

The current study used the Chinese version of ATTA (Chen, 2006), which has been extensively tested and has proven its validity in the Taiwanese sample (Shen and Lai, 2014; Wang, 2012). Chen (2006) reported that the test-retest reliability was .340-.682 $(\mathrm{p}<.01)$. The verbal part of the correlational coefficient in criterion-referenced creativity indicators was $.457(\mathrm{p}<.01)$, and the figural part was $.368(\mathrm{p}<.01)$. Since the participants in the current study were going to be young Chinese adults in Macau, the ATTA was selected as a measurement tool.

We used the Verbalizer-Visualizer Questionnaire (VVQ; Richardson, 1977) to assess the visualizer-verbalizer dimension. The original VVQ contains 15 items and asks participants to judge how they use to their style of thinking via a true-false response. The current study used a 7-point Likert-type scale, ranging from 1 (strongly disagree) to 7 (strongly agree), following Mayer and Massa's (2003) suggestion. Mayer and Massa reported that the Cronbach alpha for the VVQ was .71. Two averaged scores were calculated: one for verbal cognitive style and one for visual cognitive style.

The participants were first informed of the purpose of the study and the procedure of the test. They were asked to provide basic information, such as their gender and age. Then the ATTA was conducted, and each task was allowed three minutes for completion. It took about 10 minutes to finish this session. Finally, our respondents were asked to evaluate creative products via the 15 -item CPSS and the VVQ. It took about 20 minutes to complete the evaluation. The whole process was completed within 30 minutes.

Inspired by Besemer's (1998) study, the current study used three chairs as the prompt and collected them from the Vitra Design Museum (http://www.design-museum.de/ en/collection/100-masterpieces.html). On its website, the museum exhibits 100 masterpieces of chairs from 1900 to 1990 . The criteria for selecting chairs is highly novel and also beyond the expected functionality of the chars for real-life use. Three slides of three chair illustrations as stimulus items were selected by the researcher and evaluated by our participants as follows: Marc Newson, Lockheed Lounge, 1985/86; Verner Panton, Living Tower, 1968/69; and Achille and Pier Giacomo Castiglioni, Mezzadro, 1954/57.

\section{RESULTS}

Pearson correlation coefficient was used to examine relationships among nine variables. Table 1 shows that fluency was positively correlated with originality, elaboration, flexibility, novelty, and resolution. There were no statistically significant correlations between originality and other variables. Elaboration was only statistically significant correlated with flexibility. Novelty was positively correlated with resolution, elaboration and synthesis, and verbal and visual cognitive style. Elaboration and synthesis was also positively correlated with verbal and visual cognitive style. Finally, verbal and visual cognitive styles were posi- 
tively correlated with each other.

Table 1. Pearson correlation coefficients among nine variables.

\begin{tabular}{|c|c|c|c|c|c|c|c|c|c|}
\hline Variable & 1 & 2 & 3 & 4 & 5 & 6 & 7 & 8 & 9 \\
\hline 1. Fluency & -- & & & & & & & & \\
\hline 2. Originality & $.23 * *$ & -- & & & & & & & \\
\hline 3. Elaboration & $.20 *$ & .13 & -- & & & & & & \\
\hline 4. Flexibility & $.34 *$ & .12 & $.27 * *$ & -- & & & & & \\
\hline 5. Novelty & $.18 *$ & .01 & .03 & -.05 & -- & & & & \\
\hline 6. Resolution & $.17^{*}$ & .06 & -.01 & -.01 & $.51 * *$ & -- & & & \\
\hline $\begin{array}{l}\text { 7. Elaboration and } \\
\text { synthesis }\end{array}$ & .16 & .11 & .10 & .09 & $.51 * *$ & $.74 * *$ & -- & & \\
\hline $\begin{array}{l}\text { 8. Verbal cognitive } \\
\text { style }\end{array}$ & .11 & .11 & .12 & .02 & $.42 * *$ & $.38 * *$ & $.42 * *$ & -- & \\
\hline $\begin{array}{l}\text { 9. Visual cognitive } \\
\text { style }\end{array}$ & .05 & .04 & .10 & -.01 & $.48 * *$ & $.45 * *$ & $.52 * *$ & $.61 * *$ & - \\
\hline
\end{tabular}

To better understand the interactions among these variables, structural equation modeling (SEM) was used. A visual diagram is shown in Figure 1.

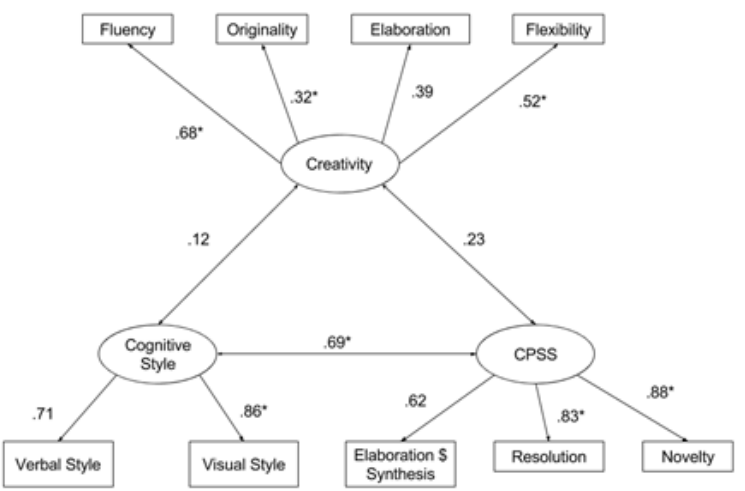

Figure 1. Standardized coefficients for model of creativity, cognitive style, and CPSS. $* \mathrm{p}<.05$.

Overall model fit shows that $\chi 2=26.89$, $\mathrm{df}=24, \mathrm{p}=.31, \chi 2 / \mathrm{df}=1.12, \mathrm{GFI}=.959, \mathrm{CFI}$ $=.991, \mathrm{NFI}=.992, \mathrm{RMSEA}=.03$. Based on Hair, Black, Babin, Anderson, and Tatham's (2006) guidelines for establishing acceptable model fit, the results show that our model attained a reasonable good fit. When examining the relationships among creativity, cognitive style, and CPSS, we found that only cognitive style and CPSS were significantly correlated $(\mathrm{r}=.69)$. The estimates relationships (paths) are also shown in Figure 1. When we looked at the first construct creativity, we found that the estimated regression coefficients for fluency, originality, elaboration, and flexibility, were $.68, .32, .39$, and .52 , respectively, and the sizes of these coefficients indicated that fluency has the biggest impact on creativity. For cognitive style, we found that visual cognitive style had the strongest impact (.86). For CPSS, novelty had the strongest impact (.88).

\section{DISCUSSIONS}

The present study found partial support for the associations between cognitive style, creativity, and evaluations of creative products. Based on zero-order correlations, visual and verbal cognitive styles were moderately and positively correlated to three components of CPSS (novelty, resolution, and elaboration and synthesis). The results of the SEM further confirm this relationship between cognitive style and CPSS $(r=.69, p<.05)$

Unexpectedly, both cognitive styles were not associated with the four components of creativity (fluency, originality, elaboration, and flexibility). It may be that the VVQ is not a proper measure for capturing creativity as measured by divergent-thinking tests like the ATTA in the current study. Although the VVQ is a major instrument used in research related to the visualizer-verbalizer dimension (Mayer and Massa, 2003), our study seems to suggest that the visualizer-verbalizer dimension did not fit the criterion of creativity. Based on our knowledge, studies involving VVQ and creativity are scarce, and so more research is needed to further confirm connections between visualizer-verbalizer dimension and creativity.

Concernig the relationship between cre- 
ativity nd CPSS, we found that only fluency was positively related to novelty and resolution This suggests that fluency is probably te most important variable in creativity (Runco and Acar, 2012), which is also supported by our SEM model. Moreover, according to the results from SEM results, creativity was not significantly related to cognitive style and CPSS.

Overall, our findings suggest that individuals' cognitive style, not their creative potential, was related to their assessment of creative products. Our results are consistent with other studies that suggested that individual differences in visual-verbal cognitive style are valid (Choi and Sardar, 2011) and have an impact on the ability to assess creative products. In the SEM model, we found that in cognitive style, visual style is more important than verbal style and in the CPSS, novelty is the most influential variable.

While our results are informative, several limitations should be noted when interpreting the findings of the current study. For instance, we used a divergent thinking test rather than real-life creative performance as the index of creativity. Although divergent thinking tests enjoy popularity in the creativity literature, several issues with the scoring systems were discussed in the literature (Silvia et al., 2008). Moreover, several scholars suggest that the real-life creative achievements generated by participants and evaluated by experts may be better than divergent thinking tests for capturing creative potential (Kaufman et al., 2008). As a result, for further research, it would be prudent to use other approaches and methods to accurately assess creativity. Another salient limitation is that our sample was recruited from one institution and one ethnic group. Cross-cultural studies seem to a promising direction for further validating the current findings. Finally, our study was a correlational study in nature. In terms of research design, using an experimental study can provide robust findings for future researchers to understand the interplay among these three variables.

\section{CONCLUSIONS}

The relationship among cognitive style, creativity, and assessment of creative products by Chinese undergraduates in Macau was partially supported by our study. In addition to contributing to the literature, the present study has direct implications for instructional prac- tices in art and design education. Our finding that cognitive style was related to assessment of creative products implies that when educators ask their students to evaluate creative products and provide feedback, teachers should take students' cognitive style in terms of the visual-verbal dimension into consideration. Based on the present findings, visual cognitive style was more important that verbal cognitive style for assessing creative products. This implies that visually based instructional methods should be used and emphasized during the assessment session.

The practical implications of the current study are that for art and design educators, it is necessary to consider their students' cognitive style in order to facilitate creativity in the classroom. In our sample, we found that visual style is more important than verbal style, which might reflect their majors-art and design. Additionally, our study successfully demonstrate that the usefulness of the CPSS. Specifically, in art and design education, peer critique and peer feedback are essential training for students. Consequently, it is suggested that educators could bring the CPSS into their curriculum development. The CPSS could serve as a guideline for art and design students to assess others' works. Finally, we used ATTA as the indicator of creative potential. In the creativity assessment market, there are numerous possible options for researchers to use. We suggest that for future researchers alternative method is beneficial. For example, we could ask participants to create real art and design works and then these design works could be evaluated by experts. The researchers could employ the CAT, which has been discussed in our literature review. In short, the current study presents some aspects of creativity, which has important implications for students of creativity.

\section{ACKNOWLEDGEMENTS}

The author gratefully appreciates all research participants and anonymous reviewers from the journal. Also I would like to thank to Dr. Beauford for her statistical knowledge and tremendous help.

\section{Conflict of interests}

The author declare no conflict of inter- 


\section{REFERENCES}

Al-Salameh, E. M. (2011). A study of Al-Balqa' applied university students cognitive style. International Education Studies, 4(3), 189-193, https://doi. org/10.5539/ies.v4n3p189

Amabile, T. M. (1982). Social psychology of creativity: A consensual assessment technique. Journal of Personality and Social Psychology, 43(5), 997-1013, https://doi.org/10.1037/00223514.43 .5 .997

Baer, J. \& McKool, S. S. (2009). Assessing creativity using the consensual assessment technique. In C. S. Schreiner (Ed.), Handbook of research on assessment technologies, methods, and applications in higher education (pp. 65-77). Hershey, PA: IGI Global, https://doi.org/10.4018/978-160566-667-9.ch004

Besemer, S. P. (1998). Creative product analysis matrix: Testing the model structure and a comparison among products - Three novel chairs. Creativity Research Journal, 11(4), 333-346, https://doi. org/10.1207/s15326934crj1104 7

Besemer, S. P., \& O'Quin, K. (1986). Añalyzing creative products: Refinement and test of a judging instrument. Journal of Creative Behavior, 20, 115 126, https://doi.org/10.1002/j.2162-6057.1986. tb00426.x

Besemer, S. P., \& Treffinger, D. J. (1981). Analysis of creative products: Review and synthesis. Journal of Creative Behavior, 15(1), 158-178, https:// doi.org/10.1002/j.2162-6057.1981.tb00287.x

Carson, S. H., Peterson, J. B., \& Higgins, D. M. (2005). Reliability, validity, and factor structure of the creative achievement questionnaire. Creativity Research Journal, 17(1), 37-50, https://doi. org/10.1207/s15326934crj1701 4

Chen, C. Y. (2006). Abbreviated Torrance Test for Adults manual in Chinese Version. Taipei: Psychology Publisher. https://www.sciencedirect. com/science/article/pii/S1877042814012191

Choi, J., \& Sardar, S. (2011). An empirical investigation of the relationships among cognitive abilities, cognitive style, and learning preferences in students enrolled in specialized degree courses at a Canadian college. The Canadian Journal for the Scholarship of Teaching and Learning, 2, Article 5, https://doi.org/10.5206/cjsotl-rcacea.2011.1.5

Dew, R. (2009). Cognitive style, creativity framing and effects. Journal of Creative Behavior, 43(4), 234-261, https://doi. org/10.1002/j.2162-6057.2009.tb01317.x

Erkan Yazici, Y. (2013). Effects of spatial experiences $\&$ cognitive styles in the solution process of space-based design problems in the first year of architectural design education. International Journal of Technology and Design Education, 23(4), 1005-1015, https://doi.org/10.1007/ s10798-012-9220-x

Goff, K., \& Torrance, E. P. (2002). Abbreviated Torrance Test for Adults manual. Bensenville, IL: Scholastic Testing Service. http://psycentre. apps01.yorku.ca/drpl/commercial-test/abbreviated-torrance-test-adults-atta

Hadani, H., \& Jaeger, G. J. (2015). Inspiring a generation to create: Critical components of creativity in children [White paper]. Sausalito, CA: Center for Childhood Creativity. http://www.csus.edu/ coe/profiles/assets/jaeger-garret-j.pdf

Hair, J. F., Black, W. C., Babin, B. J., Anderson, R. E., \& Tatham, R. L. (2006). Multivariate data analysis. Upper Saddle River, NJ: Pearson. https://www.pearson.com/us/higher-education/ program/Hair-Multivariate-Data-Analysis-7thEdition/PGM263675.html

Harder, J. T., Czyzewski, A., Sherwood, A. L. (2015). Student self-efficacy in a chosen business career path: The influence of cognitive style. College Student Journal, 49(3), 341-354. $\mathrm{https} / / / \mathrm{s} 3$.amazonaws.com/academia.edu.documents/41314068/College student journal Halland et al.pdf?AWSAccessKeyId=AKIAIW OW $\bar{Y} Y \bar{G}$ G2Y53UL3A\&Expires $=1519478$ $453 \&$ Signature $=7 \mathrm{nOWMJ3EVZT7xaNWMeA}$ $\mathrm{cVZiKmvQ}=\&$ response-content-disposition=inl ine $\% 3 \mathrm{~B}$ filename $=$ Mindfulnh

Kaufman, J. C., \& Baer, J. (2012). Beyond new and appropriate: Who decides what is creative? Creativity Research Journal, 24(1), 83-91, https:// doi.org/10.1080/10400419.2012.649237

Kaufman, J. C., Bear, J., \& Cole, J. C. (2009). Expertise, domains, and the Consensual Assessment Technique. Journal of Creative Behavior, 43(4), 223233, https://doi.org/10.1002/j.2162-6057.2009. tb01316.x

Kaufman, J. C., Baer, J., Cole, J. C., \& Sexton, J. D. (2008). Acomparison of expert and nonexpert raters using the Consensual Assessment Technique. Creativity Research Journal, 20(2), 171-178, https://doi.org/10.1080/10400410802059929

Kaufman, J. C., Lee, J., Baer, J., \& Lee, S. (2007). Captions, consistency, creativity and the consensual assessment technique: New evidence of reliability. Thinking Skills and Creativity, 2(2), 96-106, https://doi.org/10.1016/j.tsc.2007.04.002

Kozhevnikov, M., Kozhevnikov, M., Yu, C. J., \& Blazhenkova, O. (2013). Creativity, visualization abilities, and visual cognitive style. British Journal of Educational Psychology, 83(2), 196209, https://doi.org/10.1111/bjep.12013

Lo, J.-J., Chan, Y.-C., Yeh, S.-W. (2012). Designing an adaptive web-based learning system based on students' cognitive styles identified online. Computers \& Education, 58(1), 209-222, https://doi. org/10.1016/j.compedu.2011.08.018

Mayer, R. E., \& Massa, L. J. (2003). Three facets of visual and verbal learners: Cognitive ability, cognitive style, and learning preference. Journal of Educational Psychology, 95(4), 833-846, https://doi.org/10.1037/0022-0663.95.4.833

Noppe, L. D. (1985). The relationship of formal thought and cognitive styles to creativity. Journal of Creative Behavior, 19(2), 88-96, https://doi. org/10.1002/j.2162-6057.1985.tb00641.x

Pektas, S. T. (2010). Effects of cognitive styles on 2D drafting and design performance in digital media. International Journal of Technology and Design Education, 20(1), 63-76, https://doi. org/10.1007/s10798-008-9060-x

Richardson, A. (1977). Verbalizer-visualizer: A cognitive style dimension. Journal of Mental Imagery, 1, 109-126. http://journals.sagepub.com/ doi/abs/10.2466/pms.1998.86.1.227

Runco, M. A., \& Acar, S. (2012). Divergent thinking as an indicator of creative potential. Creativity Research Journal, 24(1), 66-75, https://doi.org/ 10.1080/10400419.2012.652929

Runco, M. A., Paek, S. H., \& Jaeger, G. (2015). Is 
creativity being supported? Further analyses of grants and awards for creativity research. Creativity Research Journal, 27(1), 107-110, https://doi.org/10.1080/10400419.2015.992692

Shi, C. (2011). A study of the relationship between cognitive styles and learning strategies. Higher Education Studies, 1, 20-26, https://doi.org/10.5539/ hes.v $1 \mathrm{n} 1 \mathrm{p} 20$

Shen, T., \& Lai, J.-C. (2014). Exploring the relationship between creative test of ATTA and the thinking of creative works. Procedia - Social and Behavioral Sciences, 112, 557-566, https://doi. org/10.1016/j.sbspro.2014.01.1202

Silvia, P. J., Winterstein, B. P., Willse, J. T., Barona, C. M., Cram, J. T., Hess, K. I., Martinez, J. L., \& Richard, C. A. (2008). Assessing creativity with divergent thinking tasks: Exploring the reliability and validity of new subjective scoring methods. Psychology of Aesthetics, Creativity, and the Arts, 2(2), 68-85, https://doi. org/10.1037/1931-3896.2.2.68

Torrance, E. P. (1966). The Torrance tests of creative thinking: Norms-Technical manual (Research edition). Lexington, MA: Personnel Press. https://books.google.com.tw/books/ about/Torrance Tests of Creative Thinking. html?id=4dUYAAACAAJJ\&redir_esc $=y$

Treffinger, D. J., Young, G. C., Selby, E. C., \& Shepardson C. (2002). Assessing creativity: A guide for educators (RM02170). Storrs: University of Connecticut, The National Research Center on the Gifted and Talented. https://files.eric.ed.gov/ fulltext/ED505548.pdf

Tsai, K. C. (2016a). Quasi-experts' assessments of creative products: An evaluation using a sample of design students. British Journal of Education, Society \& Behavioral Science, 12(3), 1-7. http://www.journalrepository.org/media/journals/BJESBS 21/2015/Oct/Tsai1232015BJESBS21057.pdf

Tsai, K. C. (2016b). Fostering creativity in design education: Using the creative product analysis matrix with Chinese undergraduates in Macau. Journal of Education and Training Studies, 4(4), 1-8, https://doi.org/10.11114/jets.v4i4.1247

Wang, A. Y. (2012). Exploring the relationship of creative thinking to reading and writing. Thinking Skills and Creativity, 7, 38-47, https://doi. org/10.1016/j.tsc.2011.09.001

White, A., Shen, F., \& Smith, B. L. (2002). Judging advertising creativity using the Creative Product Semantic Scale. Journal of Creative Behavior, 36(4), 241-253, https://doi. org/10.1002/j.2162-6057.2002.tb01067.x 